\title{
Felipe y la negociación de los Tratados de Utrecht: bajo los dictados del mejor abuelo del mundo
}

\author{
Joaquím Albareda i Salvadó \\ Univesitat de Pompeu Fabra \\ joaquim.albareda@upf.edu
}

Fecha de recepción: 28/04/2013

Fecha de aceptación: 22/06/2013

\section{RESUMEN}

La historiografía ha puesto de relieve que en las conversaciones que dieron lugar a los tratados de Utrecht (1713) Luis XIV asumió la representación de los intereses de España. Profundizando en el tema pretendemos explicar cuál fue la actitud de Felipe V en el transcurso de las mismas. Las instrucciones que remitió a sus plenipotenciarios, así como la correspondencia que intercambió con Luis XIV, además del testimonios de otros protagonistas, constituyen una magnífica base documental para llevar a cabo este cometido. Todo ello nos permite mostrar la complejidad de la negociación, aclarar la relación entre los dos reyes, no exenta de tensiones, al tiempo que explicar las ambiciones y las frustraciones de Felipe V, siempre supeditado a los dictados del rey de Francia.

Palabras clave: Felipe V, Luis XIV, tratados de Utrecht, guerra de Sucesión de España, relaciones internacionales, siglo XVIII.

\section{Philip V of Spain and the negotiations of the Treaties of Utrecht: Under the dictates of 'the World's Best Grandfather'}

\begin{abstract}
Historiography has traditionally emphasized the representation of the Spanish interests by Louis XIV of France in the talks that led to the Treaties of Utrecht (1713). In order to explore this issue, this contribution examines Philip V's attitude during the negotiations. For this, an excellent documentary basis is the instructions that the Spanish king gave to his ambassadors, the correspondence that he exchanged with Louis XIV and finally the testimonies of other protagonists. This allows us to show the complexity of the negotiations, clarify the relationship between the two kings -not without tension-and, ultimately, to explain Philip V's ambitions and frustrations under the constant dictates of his grandfather, the King of France.
\end{abstract}

Key words: Philip V of Spain, Louis XIV of France, Treaties of Utrecht, War of the Spanish Succession, international relations, $18^{\text {th }}$ century. 
En 1710, consumado el fracaso de las conversaciones de Gertruydenberg, entre los políticos británicos cobró fuerza la idea de forjar un acuerdo con Francia mediante una transacción que fuera favorable a sus intereses comerciales y abandonar la guerra iniciada en 1702. Influyeron en ello una opinión pública cada vez más favorable a la paz, al tiempo que la derrota austracista de Villaviciosa en diciembre de aquel año. A fin de cuentas, la entrada en la contienda por parte de los ingleses se justificó, en buena medida, por la necesidad de intervenir en el comercio de Indias, tal como expuso en 1707 Joseph Addison, redactor del periódico Spectator y Secretario de Estado una década más tarde ${ }^{1}$. En otoño, el nuevo gobierno de los tories liderado por Robert Harley (al frente del Exchequer) y Henry de Saint-John (secretario de Estado para la guerra), futuro vizconde de Bolingbroke, optó por esta vía a pesar de que hizo gala de una actitud ambigua. Si bien reiteraba su apoyo a las aspiraciones de los aliados -especialmente al retorno de la monarquía hispánica a los Habsburgo-, empezó a negociar secretamente con la corte de París la conservación de Felipe V en el trono hispánico a cambio de importantes concesiones en Europa y América ${ }^{2}$. En efecto, el gobierno sentó las bases de lo que serían los acuerdos de paz, entre los que destacan la negociación bilateral con Francia, a expensas de los aliados, y el principio de que Felipe V debería conservar España y las Indias, a cambio de importantes concesiones comerciales en Europa y América. Eward Villiers Earl of Jersey y l'abbé François Gaultier, agente del secretario de Estado francés marqués de Torcy, residente en Inglaterra, establecieron los primeros contactos ${ }^{3}$. A finales de 1710 el marqués de Torcy recibió una clara declaración de intenciones del nuevo ministerio británico:

We will no longer insist on the entire restoration of the Monarchy of Spain to the House of Austria, or if we do it will be weakly and pro forma, and we shall be content provided France and Spain will give us good securities for our commerce; and as soon as we have got what we need and have made our bargain with the two crowns, we wil tell our Allies ${ }^{4}$.

Los contactos tomaron un camino certero en enero de 1711 (mediante Gaultier, que el 15 de aquel mes llegaba a su país) de forma que el 22 de abril de 1711, sólo cinco días después de la muerte del emperador José I, Torcy proponía un documento de negociación a los británicos -entre cuyos puntos se hallaban el reconocimiento de garantías para el comercio británico en España, en las Indias y en el Mediterráneo,

1 Este estudio se inscribe en la investigación de los proyectos del Ministerio de Ciencia e Innovavión (HAR2011-26769) España y los tratados de Utrecht y del Grup d'Estudi de les Institucions $i$ de la Societat a la Catalunya moderna (segles XVI-XVIII), Generalitat de Catalunya (2009SGR318). Quiero agradecer la inestimable colaboración de Elena Jiménez, de la Sección de Referencias del Archivo Histórico Nacional. Addison, J.: "The present State of the War", en Miscellaneous Works in Verse and Prose, vol. 3, Londres, J. and R. Tonson and S. Draper, 1746. Agradezco a Josep Fontana que me haya proporcionado esta obra.

2 Frey, L., Frey, M.: The Treaties of the War of the Spanish Succession, Westport, Connecticut, Greenwood Press, 1995, pp. 14-15.

3 Gregg, E.: Queen Anne, New Haven and London, Yale University Press, 2001, p. 335; Trevelyan, G. M.: England under Queen Anne. The Peace and the Protestant Succession, London, New Cork, Toronto, Longmans, Green and Co, 1934, pp. 176-178.

4 TRevelyan, op.cit., (nota 3), p. 88. 
una Barrera para los Países Bajos y el inicio inmediato de negociaciones- $-^{5}$. El 28 de abril, Gaultier regresaba a Londres con el beneplácito de Luis XIV ${ }^{6}$. Transcurridos dos meses, el 1 de julio de 1711 el poeta y agente británico Matthew Prior respondía mediante una propuesta en la que además de reclamar que las coronas de Francia y de España nunca pudieran unirse, fijaba las reivindicaciones territoriales y comerciales británicas. Entre otras, Gibraltar, Mahón, el asiento de negros y las mismas ventajas comerciales que disfrutaban los franceses ${ }^{7}$. Tras diversos encuentros entre Prior, Gaultier y Nicolas Mesnager (plenipotenciario de Francia, comerciante de Rouen y buen conocedor del comercio con Africa y América) ${ }^{8}$, el resultado de la negociación, a espaldas de Holanda para que no pudiera reclamar compensaciones comerciales, se tradujo en tres documentos preliminares, el 27 de septiembre de 1711 (firmado el 8 de octubre $)^{9}$, cuyo contenido prefiguró los acuerdos posteriores de Utrecht y concretó los beneficios obtenidos por Gran Bretaña. Las bases del documento secreto de las concesiones francesas incluían el reconocimiento de la sucesión protestante, las negociaciones para un acuerdo comercial franco-británico, la destrucción de las fortalezas de Dunkerke, la retención británica de Gibraltar y Mahón, el asiento de esclavos para los británicos y privilegios comerciales en España parecidos a los que había disfrutado Francia ${ }^{10}$.

Entretanto, le correspondió al enviado extraordinario de Francia marqués de Bonnac la ardua tarea de transmitir a Felipe V las directrices de Luis XIV e intentar convencerle de que las asumiera. El 2 de septiembre de 1711 fue recibido por el rey, la reina y la princesa de los Ursinos, el núcleo duro que tomaba las decisiones de estado, según afirma la memoria que el rey de Fancia entregó a Bonnac ${ }^{11}$. Entre otras cuestiones, la memoria subrayaba la conveniencia de una unión estrecha entre Francia y España sin que esta tuviera visos de dependencia por parte de España. Advertía al enviado del carácter "vrai et plain de droiture" de Felipe V cuyo proceder podía inducirlo a la equivocación, puesto que el rey estaba convencido de que los acontecimientos afortunados del último año eran fruto de su firmeza: "l'exces de confiance lui paroit une vertu et ces idées flatteuses sont d'autant plus difficiles à detruire dans

5 Drift, A.: The History of His Own Time. Compiled from the original manuscripts of Matthew Prior, London, Editor, 1740, pp. 338-340.

6 Guerrero, J. analiza con detalle los primeros contactos en El tratado de paz con Inglaterra de 1713. Orígenes y culminación del desmembramiento de la monarquía española, Tesis doctoral, Universidad Autónoma de Madrid, 2008, pp. 350-369.

7 DrifT, op. cit., (nota 5), pp. 345-347.

8 Sobre Mesnager, BÉLY, L.: Espions et ambassadeurs au temps de Louis XIV, Paris, Fayard, 1990, pp. 576-595.

9 Guerrero, op. cit., (nota 6), pp. 379-381.

10 BÉLy, L.: Les relations internationales en Europe, XVIIe-XVIIIe siècles, París, PUF, 1992, pp. 419-420; BÉly, op. cit., (nota 8), p. 41; GreGG, op. cit., (nota 3), pp. 341-342; El marqués de Torcy da cuenta de los diversos documentos que fueron intercambiando: Memoirs of the marquis of Torcy, Secretary of State to Lewis $X I V$, vol. 2, London, P. Vaillant, 1757, pp. 128-129, 138-141 y 153-155; TrEVELYAN, op. cit., (nota 3), pp. 185187. Los documentos preliminares pueden verse en $A$ report from the Comitte of Secrecy appointed by order of the House of Commons, reported on the Ninth of June 1715 by the R. H. Robert Walpole, London, Jacob Jonson, Timothy Goodwin, Bernard Lintoll and William Taylor, 1715, Appendix, pp. 3-10.

11 Morel-Fatio, A., Lèonardon, H.: Recueil des instrucions données aux ambassadeurs et ministres de France, 12, Espagne, Paris, Félix Alcan, éditeur, 1898, pp. 187-214. 
son esprit qu'il est opiniâtré dans ses sentimens, en sorte que si, malhereusement, il prend de mauvais partis, il ne sera pas facile de lui faire connoître l'erreur'. Por esta razón valoraba positivamente la influencia que la reina ejercía en él, puesto que era del parecer que convenía que alguien le gobernara ${ }^{12}$. El cometido principal de Bonnac era convencer a Felipe $\mathrm{V}$ de la urgencia de la firma de la paz, "qu' il aura lieu de la regarder comme avantageuse, à quelque prix qu'il puisse 1'acheter”, al objeto de seguir siendo rey de España y de las Indias ${ }^{13}$. Para lograr aquel objetivo, las instrucciones aconsejaban a Bonnac que debía mantenerse firme en su posición y que en el caso de que no pudiera persuadir a Felipe V no debía ceder, sino al contrario, seguir las órdenes del rey de Francia. Debía convencerle de que el tiempo apremiaba y que no podía dejar pasar una ocasión favorable como aquella para poner fin a la guerra.

Los holandeses no fueron informados de las negociaciones hasta el mes de octubre de 1711 y se indignaron al conocer los acuerdos que perjudicaban a sus intereses comerciales. Al mismo tiempo, la inquietud del emperador era creciente ${ }^{14}$. Los británicos, tal com habían hecho durante toda la guerra, jugaban con ventaja sin mostrar sus cartas a los aliados. Las instrucciones de la reina Ana a los plenipotenciarios británicos constituyen una buena muestra de su sutil juego diplomático:

En cas que l'ennemy objecte, comme les ministres imperiaux ont fait, que le second article des sept qui ont eté signés par le sieur Mesnager porte que le duc de Anjou demeurera sur le throne d'Espagne, vous insistirez que ces articles dans toute leur entendue lient bien la France, mais qu'ils ne nous métent point, ni nos alliez, dans aucun engagement positif qu'ils ont eté receu seulement comme des motifs qui nous purroient incluire à ouvrir des conférences, et qui une stipulation à prendre des mesures pour empecher que les couronnes de France et d'Espagne ne soient jamais reunies sur une même tête ${ }^{15}$.

Por si fuera poco, la situación se complicó con la muerte de diversos posibles herederos al trono de Francia: el hijo de Luis XIV y padre de Felipe V, Luis, Gran Delfín, en abril de 1711; en 1712 el hermano de Felipe V, duque de Borgoña. Posteriormente, en 1714, falleció su hermano pequeño el duque de Berry quedando la línea masculina prácticamente extinguida. Felipe $\mathrm{V}$ se convertía, entonces, en el candidato al trono francés mejor posicionado ya que el posible sucesor, el futuro Luis XV, sólo contaba dos años y su salud era precaria. Así pues, Luis XIV confiaba en que su nieto sería rey de Francia e intentó convencerlo de ello. Pero, al mismo tiempo, no tenía reparo en asegurar en las conversaciones de Utrecht que no tendría lugar la unión de las coronas de Francia y de España. La esposa de Felipe V, María Luisa Gabriela de Saboya, apoyó al Rey Sol y propuso a su marido que se convirtiera en regente de Francia y rey de España o a la inversa, idea que rechazó de pleno la diplomacia británica. Al final Felipe V, más autónomo de lo que habría deseado su abuelo, el 22 de abril de 1712

\footnotetext{
12 Ibidem, pp. 199-200.

13 Ibidem, p. 203.

14 Albareda Salvadó, J.: La guerra de Sucesión de España (1700-1714), Barcelona, Crítica, 2010, pp. 323-328.

15 "Traduction d'un extrait des instructions donées par S.M. la Reyne à ses Plenipotentiaires...", 1711, Haus-, Hof-, und Staatsarchiv Wien (H.H.St.), Spanien-Varia Kart.50, f. 1.
} 
había resuelto renunciar al trono de Francia, y apostar por la corona hispánica que ya había ceñido y por la fidelidad que le habían tributado los territorios de Castilla, cuyo apoyo resultó determinante en los momentos más críticos de la guerra ${ }^{16}$.

Certificando el cambio de rumbo británico, en febrero de 1712, el mando de los ejércitos británicos recayó en el duque de Ormond y éste, en el mes de mayo, recibió órdenes secretas del gobierno siguiendo los dictados de Harley y de Bolingbroke, de evitar batallas o sitios, lo que significaba, lisa y llanamente, abandonar a los aliados en el campo de batalla ${ }^{17}$. En julio, el propio Ormond anunció la suspensión de las hostilidades entre británicos y franceses, y el armisticio fue declarado el 21 de agosto ${ }^{18}$.

\section{LAS INSTRUCCIONES DE FELIPE V A LOS PLENIPOTENCIARIOS}

A partir de entonces, y paralelamente al avance francés frente a los ejércitos imperiales, la guerra dejó paso a la diplomacia entre Londres y París, que fraguó una solución casi impuesta a Madrid, mientras Francia procuraba estimular la rivalidad entre los holandeses y los británicos.

Felipe V, mediante Manuel de Vadillo, envió instrucciones a los plenipotenciarios que debían representarle en Utrecht, el duque de Osuna, el marqués de Monteleón y el conde de Bergeyck. Se trata de un extenso documento, de cuarenta y cinco puntos, cuyos principios generales resultaban contradictorios fruto, sin duda, de los condicionantes que coartaban absolutamente el margen de acción de Felipe V. Reyes Fernández Duran, al referirse a aquellas instrucciones, no ha dudado en afirmar que "demuestran la falta de realismo de la corte española sobre su poder de negociación y su desconocimiento de lo que ya había sido negociado por los franceses con los ingleses" ${ }^{19}$. Si la primera afirmación parece bien fundada, la segunda es discutible, a tenor de la correspondencia que tendremos ocasión de comentar. Por su parte, Joaquín Guerrero ha calificado el documento de utópico y sincero, que refleja las genuinas aspiraciones de Felipe $\mathrm{V}$ en materia de política exterior, especialmente en los territorios italianos ${ }^{20}$.

La instrucción, fechada el 28 de diciembre de $1711^{21}$, resulta de gran interés para apreciar el difícil papel de Felipe $\mathrm{V}$ en aquel momento decisivo en que iba a clausurarse el conflicto internacional $\mathrm{y}$, en consecuencia, a establecer las correspondientes concesiones tanto políticas como territoriales y comerciales. Lo primero que llama la atención es que el monarca actua como soberano plenamente autónomo cuando, en realidad, Gran Bretaña y Francia hacía ocho meses que habían llegado a acuerdos preliminares sin que él hubiera podido intervenir, situación que se prolongó en la

16 Lo explica muy bien Bély, L.: La société des princes. XVIe-XVIIIe siècle, París, Fayard, 1999, pp. $336-341$.

17 Hoppit, J.: A Land of Liberty? England 1689-1727, New York, Oxford University Press 2000, pp. 305 y 120; Coward, B.: The Stuart Age England, 1603-1714, Londres, Longman, 2003 (3 ${ }^{\mathrm{a}}$ ed.), p. 438.

18 LynN, J. A.: The Wars of Louis XIV. 1667-1714, Londres, Longman, 1999, p. 351.

19 Fernández Durán, R.: La corona española y el tráfico de negros. Del monopolio al libre comercio, Madrid, Ecobook, 2011, p. 121.

20 Guerrero, op. cit., (nota 6), pp. 392-393.

2128 de diciembre de 1711, Archivo Histórico Nacional (AHN), Estado, leg. 3376/2, nº 10. 
negociación de Utrecht, hasta el último momento. Aún más, se comporta como si se tratara del auténtico vencedor de la guerra y se declara tajantemente en contra de las concesiones territoriales y comerciales. No es que desconociera la realidad, puesto que Luis XIV, cuando le pareció oportuno, le tuvo al corriente de las negociaciones, aunque sino detalladamente (tarea que dejaba en manos de Bonnac), por lo menos en el sentido inequívoco de que debería aceptar importantes concesiones a los británicos. ¿Es posible que pensara que podría soslayar los acuerdos francobritánicos que él mismo afirmaba a su abuelo que aceptaría?. ¿Cabe calificar de ilusoria su actitud?. ¿O de puramente testimonial, para dejar constancia de cuáles eran sus verdaderas y maximalistas aspiraciones?. Sea como fuere, el documento, aparte de transmitir una extraña impresión, trasluce una total dependencia hacia Francia -así era en términos políticos y militares-, a pesar de la fijación de Felipe $\mathrm{V}$ de no aparentar ser un rey subalterno.

Debido al interés del documento, reproducimos un amplio extracto del mismo, respetando su articulado:

1. Por quanto por ocultos juicios de Dios haya padecido la Europa, la más sangrienta guerra, con desolación de pueblos [...] se descubren apariencias y positivas disposiciones de volver a la paz y quietud, tan apetecida y deseada de todo el orbe cristiano, y muy particularmente por mi, recomienda a los plenipotenciarios que de vuestra comprehensión y prudencia, confio os governareis con la circunspección y destreza que combiene en lo que se huviese de proponer, tratar y ajustar.

2. Vien notorio es que en la [guerra] que padezco no me introduxo la ambición de conquistas ni de estender mis dominios, sino la precisión de la propia defensa y de los que la Divina providencia fue servida a destinarme por tantos legítimos títulos de sangre, declaración, llamamiento y aclamación de mis reynos. Por lo que aspiraba a una paz segura, decente y decorosa y aconsejaba a los plenipotenciarios: Por esto la maña debe diestramente, no descubriendo combeniencia y honor en los tratados procurar alargarlos y desvanecerlos y hacer entender con verdad y firmeza a los amigos que se está assí en disposición de continuar la guerra y enmendar los subcsesos padecidos y entre los enemigos sembrar, insinuar, introducir especies que dificulten llegar a la conclusión de paz ruin.

3. Da por sentada la conformidad y acuerdo con la Francia y sus ministros [...] y nada fuera tan contrario a mi sinceridad, a mi amor y a ms intenciones que el que a ella se faltasse.

4. A la integridad de la Monarchia debe aspirarse. En esta están empeñados los intereses y deseos de todos los dominios que la componían quando entré en su posesión [...] Mi honor y mi conciencia sobre el notorio interés de dominar en las Provincias, que mis mayores mantuvieron, está empeñado igualmente. Estos fueron los supuestos sobre que recayó la declaración que hizo de mi justicia el Rey Carlos $2^{\circ}$ mi tío [...] la gloria y honor de la Francia entera y lo que más es el personal del Rey mi abuelo está más que todo empeñado con su palabra real [...] a esta integridad debe aspirarse y no se deviera pensar en un ápize que descaezca de ella. 
5. Admite que es posible que no sean enmendables los desmesurados deseos de las potencias aliadas y que para obtener la paz se debe hacer algun sacrificio [...] En estos términos, y de que se haya de combenir en alguna separación de dominios en cualquiera aunque pequeña parte se ha de disputar y defender dedo a dedo.

6. Debe assentarse como preliminar y primer supuesto indefectible y en que no se ha de contestar alteración que yo en todos cassos he de quedar con la España íntegra con las Indias, islas del Mediterráneo y Occéano, en la misma forma que las heredé quando subcedí en el trono sin que en esto pueda admitirse la menor duda [...] Y al mismo tiempo tendreis muy presente que por la situación y cercanía de las costas de Hespaña son esempcialísimas las islas de Mallorca y Menorca; por cuyo motivo, y por otras consequencias, se hace preciso el insistir en su restitución, pues aunque los ingleses por lo que les facilitan y aseguran el comercio de Levante procurarán retener a Puerto Mahón, es también muy aparente que los ministros holandeses apoyaran mi justicia por lo que este puerto pudiera perjudicar a su comercio en manos de los ingleses y así combendrá que mañosamente manegeis con los ministros de Holanda este negociado.

7. Se refiere a las pretensiones hereditarias de la casa de Austria, sobre las cuáles les advierte que no habléis sobre esto, ni lo subsciteis sino en el casso de ser compelidos a ello.

8. Alude a las investiduras del ducado de Milán y otros feudos de Italia para que se tengan presentes a fin de estimarlas a lo menos para equivalencia de otros intentos, como contrapeso.

9. Advierte que siendo constante que si se agregasen a la persona del Archiduque los estados de Flandes [...] aumentaría con ello tanto su potencia y se haría tan formidable $[\ldots]$ debe solizitarse con las más vivas instancias la incorporación de estos estados a mi corona, puesto que a su juicio podría garantizar mejor que nadie la barrera solicitada por las Provincias Unidas.

10. Apunta que estos estados, bajo soberanía de España, fueran gobernados por el elector de Baviera u otro príncipe católico hasta tanto que un infante de Hespaña pudiese ir a governarlos.

11. El mayor deseo del Archiduque se debe considerar dirigido a mantener la usurpación del Reyno de Nápoles, resistir la restitución del estado de Milán y aspirar a lo demás de italia". Frente a él, reitera los derechos que le asisten y la importancia de restablecer su posesión en dichos territorios [...] y este intento justo se puede y debe creer apoyado del interés y deseo de las más potencias de Italia y menos resistido de ingleses y holandeses que sólo pararán atención en el asunto en quanto tengan relaciones sus comercios de levante y livertad en la navegación de aquellos mares; puntos en que es muy posible no se combengan sinceramente ingleses y holandeses entre sí, por el rezelo con que cada potencia de estas mira a la otra.

13. Para ello conviene poner en indisputable claridad mis justos títulos y derechos a cada uno de los dominios de Italia, que recuerda pormenorizadamente.

14. Asentada mi notoria justicia a los dominios de Italia y la importancia de mantenerme en los que poseo y de restablecerme en los que se me usurpan en la misma 
forma que los posehí quando subcedí en toda la Monarchia; en nada que sea opuesto a este intento y que dificulte o destruya su logro se debe consentir si no es en el último desengaño de no poder evitarlo sin mayores perjuicios. Debían procurar conseguir en toda forma en que mis acciones y derechos a los dominios de Italia queden fuera de la obligación de cessión.

15. Ahora bien: Quando prevaleciese contra la razón y contra la justicia la infelicidad de que se huviese de establecer en los tratados algo en perjuicio de mis intereses de Italia $[\ldots]$ es vien considerar [...] que entre el reyno de Nápoles y el estado de Milán, es incomparablemente más importante el retener el reiyno de Nápoles [...] por ser uno de los más obstentossos y considerables de que se compone esta Monarchia. En consecuencia, se deven hacer todos los esfuerzos posibles para la reintegración de aquel reyno sin cederle nunca. Y para facilitar la comunicación entre él y Hespaña, se hace preciso procurar la reyntegración de los presidios perdidos en Toscana, lo que importa también mucho para tener en alguna suxección al duque de Florencia y ser más dueño del comercio y navegación en el Mediterráneo. Era conveniente embarazar que la casa de Austria se aumente y engrandezca con un dominio tan útil para ella como el de Milán, y solicitar al mismo tiempo recayga este en un príncipe tercero que medie entre Alemania y aquel estado, el qual recayga mejor que en otro en el duque de Saboya.

16. En relación con la participación en los tratados sostiene que para mi tubiera ventaja que los Príncipes de Italia fuesen oydos y tubiesen authoridad en los tratados, por que siendo tan de su interés se establezca en Italia alguna potencia que sirva de embarazo al duque de Saboya en sus constantes ideas de ensancharse, y de contrapesso a los austriacos en los dominios que usurpan [...] pero si la desgracia dispusiese las cossas de suerte que yo no quedase con pie en Italia, en este casso me sería perjudicial que sus príncipes quedasen incluidos en alguna forma.

17. En quanto a Hespaña combiene tener presente como punto de summa importancia que de ninguna manera se den oydos a proposición de pacto que mire a que los cathalanes se les conservne sus pretendidos fueros, pues sobre ser tan indignos de ellos. Aun que fuesen solos los que tenían en tiempo del rey Dn. Carlos $2^{\circ}$ mi tío (puesto que las dos últimas Cortes que han concluido los deja más repúblicos que el parlamento abusivo a ingleses) no es de combeniencia ni decoro que la paz general salga garante de tan vergonzosa condición ni que por ella quedase la abitual propensión de los cathalanes a la revelión, con amarras y permitido recurso a los coaligados enemigos.

18. Trata sobre el goce de derechos del patrimonio, rentas, feudos y honores de tantas familias e individuos fieles que de los dominios y provincias se desmembraren por el tratado. Advierte que en la paz de Portugal no se hizo así y que a los portugueses que quedaron en Castilla el llamado Rey de Portugal les negó las haciendas de que se siguió y sigue hasta hoy, que yo alimente a muchos con no corto dispendio de mi herario.

19. Lo mismo para las gracias, honores y privilegios que hubiera concedido, y que deberán mantenerse.

20. Para la paz que ahora haya de hacerse se abrá de tener presente la de Berbins, Pirineos, Munster, Nimega y Risvicch y qualquiera que haya de tomarse por pauta será menos mal sonante que el llamado tratado de repartimento [1700], en el qual, de manera alguna contestareis ni permitireis que de él se trate, ni como exemplo ni como 
motivo, puesto que nunca fue aprobado por España. Por lo tanto, debían escusar todo lo posible que se toque ni capitule en el presente tratado de paz con el especioso nombre de partage.

21. Los intereses genéricos de los príncipes [...] será bien tocarlos aquí para que la diversidad u oposición que entre si pueda descubrirse sirva al manejo y dirección de los míos. Especifica que Los principales que en ella intervienen son ingleses, holandeses, Imperio, el Archiduque, la Francia, Portugal y la Italia que abraza como primer agente al duque de Savoya; Papa y venecianos y todos los demás.

22. La Christiandad toda tiene el mismo interés en que haya recaydo en la persona del Archiduque la elección del Imperio, y yo especial le tengo por dificultarse con su establecimiento allí, el abrazar la Monarchia Spañola, que sobre ser iniquo le será perniciosso. Por este motivo se puede combencer con la solidez de que los reyes y príncipes que componen a Europa no han de exponerse a ser tiranizados del desmedido poder del Imperio y Monarchia unidos, que sería como universal [...] peligro tan prevenido de la larga vista de Inglaterra y Holanda, que aun menos inmediato, quando se formó el año de 1700 la escriptura del partage, no agitado entonces el discurso de la irritación de las armas y sobre las máximas del equilibrio político establecieron y explicaron en el artículo nono que todo era devajo de la condición que el dicho repartimiento no podía jamás ser reunido ni quedar en la persona de aquel que fuese emperador o Rey de romanos. De que se sigue que siéndolo el Archiduque no pueda, por máxima de política y equilibrio unibersal retener cossa alguna de lo que le aplicava el partage, cuyo último fin fue expresamente igualar las potencias.

23. Carlos VI, es de creer que aunque manifieste otra cossa, sus fines paren en retener lo que me ha usurpado en Italia como más fácil de conservar [...] con qualquier porción que consiga retener o aumentar su poder quedará tan formidable que los príncipes de Italia y el Imperio puedan llorarlo igualmente.

24. El duque de Baviera y su hermano desposehidos y finísimos coligados, es razón se restituyan íntegramente a sus estados [...] pudiera ser medio el de reconocer por rey de Prussia al elector de Brandembourg y por noveno elector al duque de Hannover; puntos en que se cree muy interesado al Archiduque y a los ingleses y holandeses, y consentir en que el príncipe Eugenio fuese infeudado en el ducado de Mantua sino huviese otros equivalentes.

25. Los intereses de la Francia deven promoverse con las mayores veras para que de sus conquistas y adquisiciones pierda lo menos que sea posible en que de su parte y de la mía será donde haya más que contrarrestar contra la porfiada obstinación de los enemigos, cuyo fin en los empeños de esta guerra, desde sus principios y muchos años antes, no ha sido el de destruir ni dividir la Monarchia de España, sino evitar que recayese y se mantenga en quien haya de conservar amistad y comunidad de intereses con la Francia y cercenar su potencia que se han figurado formidable y gravosa a su seguridad, con que manteniendose ellos en esta máxima será donde mayor dificultad se enquentre para hallanarla sin detrimento y dispendio de la Francia y mío y en que más tendrá que lucir la destreza de la negociación. En que por la Francia y por mi y por los ministros de una y otra se hace preciso haber de proceder con conformidad y buena fe, lo qual executareis hasta en el casso que pueda acaezer algun perjuicio a 
mis intereses, pues entonces devereis cumplir con una primera obligación de disputarlos y defenderlos.

26. Inglaterra y Holanda se ha de creer máxima elemental suya, querer sólo seguridad y ampliación de comercio y no extensión del dominio; oy la primera apetecerá puertos en el continente de Flandes y la segunda, Barrera de plazas y territorio impenetrable y fructífero, y entrambas comercio abentajado en Indias. Estos deseos complicados entre sí pueden ser manzana de discordia de que se saque utilidad.

27. Ambas potencias se sentirán árbitras de la paz y todas las veces que ellas encontrasen con su satisfacción no abría que hacer gran quenta del Archiduque ni del Imperio, ni importaría a mis intereses y a los del Rey mi abuelo quedasen excluidos de la paz, y con las armas en la mano, antes bien pudiera desearse mantubiesen el empeño y que portugueses los acompañasen en él, y assí todo el esfuerzo de la negociación debe dirigirse a que ingleses y holandeses satisfechos en sus intereses se aparten de la guerra y de las asistencias al Imperio y Archiduque. Unos objetivos, recuerda, que se plasmaron en el tratado de La Haya entre holandeses e ingleses, el 28 de marzo de 1702. En relación con el tema del comercio en aquel tratado, les señala que es menester en todas maneras que se esfuerze, quede el de España con estas potencias en los términos y estado que estava en tiempo del Rey Dn. Carlos $2^{\mathrm{a}}$ mi tío porque importaría poco, quedase yo con las Indias si quedava con el pesso de mantenerlas sin la utilidad de desfrutarlas porque lo que despuebla lo primero estos reynos se compensa con las utilidades que trae a ellos su tráfico.

28. Partiendo de la base de que estos son sus auténticos objetivos y de que nunca han puesto la mira ni tenido por fin de su obstinado empeño que la Monarchía quede a la casa de Austria, ni aún que esta ocupe la Hespaña [... no ny motivo para desesperar de que satisfechos en los puntos de la Varrera y comercio y puntillosa questión del reconocimiento del rey Jacobo, dejen de porfiar menos en el de la satisfacción que ellos se han establecido de regular a la Casa de Austria por las pretensiones al todo, y descendiendo por partes a discurrir en los puntos, por lo que toca a la barrera en Flandes o bien quedándome agregada con la Hespaña íntegra, Indias, islas del Occeano y Mediterráneo, o bien quedando aquellos estados que componen la Barrera, de los austríacos, o en el duque de Baviera u otro príncipe de la común satisfacción indemne y resguardada, la pureza de la religión cathólica en ellos, se puede oyr, tratar y combenir lo que pareciere conveniente y de la satisfacción de ingleses y holandeses, supuesto que esta disposizión mía a combenir en esto haya hallanado o sea medio de allanar lo que en otros puntos pudiera pejudicarme y especialmente hacia la España, Indias y todas las islas del Mediterráneo y Occeano en que en manera alguna se puede ceder nada ni dar oydos a ello.

29. En quanto a los comercios se les puede ofrecer el mismo que tenían antes de la guerra, y si bien no se propusieron más extensión en el tratado de su misma Liga hecha en siete de septiiembre del año de mil setecientos y uno [...] estenderán mucho más sus pretensiones [...] Empero sin perjuicio de lo que queda referido se les podrá abrir algún camino donde repitan sus derechos y agravios de quentas escusando los juicios legales por cuyo medio podrá establecerse un juzgado de tres o quatro comerciantes españoles nombrados por el propio comercio a quien por mi parte se confiera 
la facultad competente, donde se les oyrá bervalmente y sin apelación sus derechos, no perjucicándose las leyes y estilos de las Indias. Y assi mismo se podrá establecer que en los comercios de Indias no se permitirá a ninguna nación más ventaja de las que en este tratado quedaren establecidas y aclaradas y que a él se reducen todos los que antes de ahora, generales o particulares, públicos o secretos, se hayan hejecutado y extinguidos en todo qualesquiera género de gracias, ermisiones o previlexios que se hayan concedido en qualquiera manera.

30. Muchas otras cossas será posible que discurra y proponga la sutileza codiciossa de estas naciones doctas y versadas en las matherias de comercio. En las que no tubiere inconbeniente se les podrá complacer. Ahora bien, fija como premisa indispensable que todo quanto se oyere, tratare y acordare en matheria de comercio de las Indias ha de ser en inteligencia de que nación ninguna ha de traficar derechamente en las Indias ni ha de llegar a sus puertos y costas y que las ventajas que se les conceden y participación que se les da en aquellas utilidades han de entenderse devajo la condición de que han de salir sus mercaderías desde los puertos de Hespaña en naos mías y por manos de mis vasallos españoles, y que los retornos han de volver desde las Indias a mis puertos de Hespaña, y que en otra forma fuesse, y los navíos que llegasen de qualquiera nación se hayan de reputar y tratar como de contravando. En el caso contrario, de conceder la más mínima apertura, podría dejar destruidos mis vasallos sin la única utilidad del corto estipendio que desfrutan de las comisiones, sin la esperanza de alentarse por sí al comercio activo, mis herarios despojados de los derechos, las Indias abandonadas a la insaciable codicia de las naciones, yo sin más combeniencias en sus vastos designios que el cuydado y carga de mantenerlos para que otros los desfruten, y lo que más pesso hace en mi consideración, expuesta la religión al contagio de la heregía en la comunicación de sus profesores, a lo qual no daré lugar en el más despreciable rincón de mi Monarchia aunque fuera inevitable perder todas las coronas que la componen.

31. Sobre esta planta se hace preciso que assí el comercio extranjero como el nacional queden asegurados de que cada año o cada dos años saldrán galeones y flota como más posible fuere al tiempo determinado o poco más o menos, y de que yo daré eficaces providencias para que en los puertos de las Indias no pueda entrar ni ser admitido ningún vaxel ni embarcación que no sea tratado como de contrabando.

32. Si por parte de Inglaterra se promoviere (como punto tan principal para ella) la propiedad de la Isla de Jamayca que hasta ahora no se le ha establecido por tratado, deberán consultarle.

33. Debe tenerse muy presente que todo lo que se discurre y previene sobre permisión y ventajas en el comercio de las Indias se ha de entender solo por lo que mira a la Francia, a la Holanda y a la Inglaterra y mercaderías de sus dominios de Europa, no a otras naciones.

34. En utilidad de mis vasallos y de los frutos y géneros de mis dominios se deven también solicitar las mayores ventajas en los comercios de las naciones referidas y siendo este punto el más grave e importante al Estado [...] será menester aclarar y establecer que todo lo que estuviese concedido por qualquiera motivo de tratado, gracia, privilexio o tolerancia a qualquiera nación, sea visto concederse a mis vasallos 
[...] estipulándose se mantubiesen a reserva de poder cada soberano en sus dominios crecer o vajar a su arbitrio los derechos que se tubiesen por combenientes, y así os prevengo que este punto se estipule con igualdad a todas las demás naciones, según como se observó en tiempos de Carlos II.

35. El resentimiento de ingleses por el reconocimiento al rey Jacobo y la establecida succesión de aquel reyno en la casa de Hannover son puntos que necesariamente se pondrán sobre el tablero, no dudo que la generosidad del Rey mi abuelo hará quanto quepa por mantener un empeño tan justo, y en esto me remito a lo que por S.M. C. se executare y si llegare el aprieto a términos inevitables, podreis concurrir en el reconocimiento de la princesa Anna y de los que la subcediren por determinación de sus Parlamentos en aquella corona [...] Si se insistiere en el positivo reconocimiento, se seguirá lo que el Rey mi abuelo executare.

36. En el casso de combenir holandeses en que yo ceda la soberanía de los Payses Vajos al elector de Baviera o me obliguen a cederlos a qualquiera otro príncipe, se establecerá que el receptor quede obligado a pagar y satisfacer a los Estados Generales y al elector de Brandembourg todo lo que se les queda deviendo de los tratados que hicieron con el Rey mi tío, que Dios haya, para sobstener la última guerra contra Francia. Asimismo se hará cargo de las deudas de forrajes, pan de munición u otras, hasta que los aliados se apoderaron de aquellas povincias y las de Namur y Luzembourg. Lo mismo se hará por las otras partes de la Monarchia que fuere preciso ceder para conseguir la paz.

37. El punto en que más abrá que hacer con los enemigos será en que se persuadan a que lo que por mi parte se ofreciere será cumplido con puntualidad y permanente lo que se ajustare y la dificultad de que assí lo crean y de que den a entender que lo creen consiste en la falsa apariencia que han concevido de que la unión de mi Monarchia y la de Francia no es conformidad sino identidad y que mi respecto y reverencia al rey mi abuelo es obediencia y sumisión y nunca dexará de ser subordinación, assí lo han creydo los enemigos cuyo engaño les ha mantenido en la obstinación de la guerra. Pero a la hora de preparar la paz, la razón y la equidad quieren que se estimen las cossas como son y no como se han querido persuadir. Muchas pruevas tendreis con que aclarar la verdad y que se distinga lo que es respecto a un abuelo tan justo acrehedor a mis cariñosas veneraciones, de lo que ellos llaman subordinación y obediencia. Diferencia ay entre amar al patrio nido o a subordinar a él la Monarchia. Las angustias de la guerra necesitan a valerse de straños socorros. La gratitud a ellos no ha de atribuyrse a servidumbre [...] Las utilidades del comercio que ha logrado la Francia y a ellos les irrita, no han sido arrebatadas, sino concedidas y facilitadas del agradecimiento y del interés de que tenga disposición de ayudarme quien con fineza en mis aprietos me socorre. Una vez firmada la paz, Francia y España seguirán siendo amigas y cada una tendrá arto que hacer en dominar en si misma; ni de la generosiad del Rey mi abuelo es propio querer imperar en otra, ni de la libertad de ningún soberano se debe creer se ajuste a hacerse subalterno de otro. Los corazones de los príncipes, por amor, por gratitud, por simpatía pueden estar unidos en quanto a las personas, pero los principados, por el interés, por la elevación del spiritu y lo que más executa, por la obligación de la conciencia de cada uno, se goviernan independientes, menos en lo que la comveniencia común los conforma. 
38. En quanto a Portugal poco ocurre que preveniros, pero en todo casso combiene instar en que a lo menos si conservaren hasta la paz alguna cossa de lo que han ocupado, lo restituya en la forma que lo tomó y que desde vajo de Badajoz hasta el mar, haga frontera el río Guadiana, y excluir los oydos de qualquiera intento que los portugueses quieran proponer hacia comercio en las Indias y hacia restablecer en la isla de san Gabriel y colonia del Sacramento en que indevida y subrreticiamente se havían introducido [...] y de que mis armas durante esta guerra, justa y animosamente les arrojaron; respecto de que si se les concediese estos parages quedaría Buenos Aires y el comercio de Potossí en grandísimo peligro y, por consequencia, perdido que fuese uno y otro, podrían estenderse portugueses tanto que quedasen arriesgadísimas las Indias o la mayor parte de ellas.

39. En relación con el protocolo recomienda que estareis muy en quenta para sobstener mi decoro y representación; teniendo presentes los temperamentos de que en otros congresos se huviere ussado y regulandoos según lo que pareciere más a propósito y decente en que devo esperar que por los ministros del Rey mi abuelo se proceda con igual atención [...] para evitar discordias y dilaciones y a los enemigos la complacencia de authorizar su maliciosa creencia de que mi dignidad y mi Monarchia se hacen subalternas de la del Rey mi abuelo; por lo cual combiene que procureis escusar quanto os sea posible el llegar a términos o casos de disputa que perjudiquen mi real authoridad.

40. Como los ingleses ocuparon los años de 1703 y 1704, en el seno mexicano, la colonia llamada la Carolina, tierra firme y contigua a la Florida, y que creo que poseen todavía $[\ldots]$ os encargo pidáis la restitución de esta colonia y de todas las otras que ocupan y ocuparen en las Indias hasta la publicación de la paz.

41. En todo lo que fuere ceder de mis dominios y desmembrar de ellos, $u$ en otro qualquiera punto considerable, es menester pedir tiempo para darme quenta y esperar mi ressolución en que qualquiera dilación podrá darle a que se ofrezcan accidentes que mejoren las cosas.

42. Por mi segundo plenipotenciario saveis he nombrado al conde de Bergueick y por terzero al marqués de Monteleón, de cuyo zelo y aplicación a mi servicio noticia unibersal de los intereses de mi Monarchia y particulares de las de Flandes de que tiene tanta práctica el primero y de los de Italia el segundo.

43. Con mis ministros públicos en todas las partes donde los huviere, tendreis puntual correspondencia y les particicipareis lo que hallareis a propósito y os servireis de sus noticias y prevenciones.

44. Les ordena que se interesen por el marqués de Villena y demás prisioneros de Italia y que luego que llegueis al congresso soliciteis y procureis inmediatamente el alivio de la prisión del marqués y de los demás prisioneros y aun su livertad absoluta o temporal según las coyunturas os subministaren disposición.

45. En respuesta al injusto reconocimiento que han hecho al Archiduque, con solemnes embaxadas las repúblicas de Venecia, Génova y Luca y en persona el duque de Parma $[\ldots]$ he resuelto en satisfacción de mi real decoro que mis ministros salgan de aquellas repúblicas, y los suyos, y el del duque de Parma salgan también de mis reynos como assimismo sus cónsules y secretarios. Que sus navíos, géneros y vasallos 
no sean admitidos en mis dominios y que los navíos que ya estuvieren en mis puertos salgan de ellos dentro de quince días y que les cesen los privilegios y esempciones.

La instrucción concluye expresando el convencimiento de que vuestra comprehensión, celo y prudencia sabrán lograr el acierto de un negocio en que tanto interessa el servicio de Dios y mio y el honor y gloria de la nación española.

\section{IL Y A DES OCCASIONS OÙ IL FAUT SAVOIR PERDRE}

En claro contraste con aquellas ambiciosas e ilusorias instrucciones el intercambio epistolar de Felipe V y Luis XIV entre 1711 y 1713 pone en evidencia la incuestionable dirección política por parte del rey de Francia, aunque no faltada de contestación por parte de su nieto si bien, en última instancia y a regañadientes, acababa siguiendo sus dictados porque no tenía otra opción. Si en la primavera de 1712 el plenipotenciario francés Polignac albergaba dudas acerca de la docilidad de Felipe V, Torcy advirtió a Bolingbroke que debía esperar algunas dificultades por parte de los ministros españoles, "mais qu'elles ne seraient que pour la forme et qu'elles n'empéchêraient pas la conclusion"22.

Casi medio año antes de las instrucciones a los plenipotenciarios, asumiendo ya algunas de las concesiones a los británicos que le resultaron dolorosas, Felipe V participó a Luis XIV que el duque de Vendôme le había puesto al corriente del inicio de conversaciones con Gran Bretaña:

À l'esgard de l'éxecution du traitté fait avec l'Electeur de Bavière dont vous me parlez dans vostre lettre je me suis déja remis à ce que vous jugeriez le plus convenable de faire sur cela, ainsi c'est à vous à prendre la résolution que vous trouverez à propos, mais je vous prie encore une fois de bien péser tous les inconvénients qui peuvent rencontrer dans cette affaire et je me flatte que vous voudrez bien faire attention à ceux qui regarderont mes intérests par l'amitié que vous m'avez toujours tésmoignée et dans la quelle $j$ 'ay une entière confiance. Pour ce qui est des conditions aux quelles vous mandez au duc de Vendosme que vous aviez intention de proposer la paix pour moy à l'Angleterre, il est vray que j'ay peu faire voir à ce duc que je consentirois de luy laisser Gibraltar et le Port Mahon pourveu qu' elle consentist de son costé a me laisser paisible posseseur de l'Espagne et des Indes.

Acto seguido, matizaba:

Cépendant vous jugérez aisément combien il seroit fascheux pour moy de laisser un pied en Espagne comme Gibraltar et un port aussi considérable que celuy du port Mahon à portée de ce royaume, de laisser dit je, ces deux postes aux anglois [...] je consents à ceder Gibraltar et le Port Mahon, si l'on ne peut pas faire autrement [...] Il est certain que la base de ce traitté doit estre la seureté du commerce sans la quelle on ne doit pas s'attendre que les anglois veuillent y entrer, mais je vous avoue que la céssion d'une place dans les Indes me paroist bien térrible [...] ainsi mon intention est

22 BÉLY, op. cit., (nota 8), pp. 432 y 476. 
bien de leur asseurer leur commerce, mais je ne voudrois pas hazarder les Indes pour cela et ce point est si important que je crois que vous approuverez que je fasse réflexion sur les seuretés que je pourrai donner et que j'en discoure avec le comte de Bergeyck [...] Du reste je mets toute ma confiance dans vos bontez et je me flatte que vous agirez comme le meilleur grand pére qu'il y ayt au monde pour un petit fils qui a pour vous tous les sentiments de tendresse, de respect et de reconoissance qu'il doit ${ }^{23}$.

El rey de Francia no tardó en responder al objeto de disipar sus dudas:

Je vous assure que vous ne vous trompés pas quan vous croyez que vos intérets me sont aussy sensibles que les miens et que cest avec une peine infinie que je vous fais des propositions que nous trouvons toujours dures lorsquil s'agit de ceder quelque partie des estats que Dieu nous a donnés. Mais il y a des occasions ou il faut savoir perdre et si vous estiés possesseur tranquile de 1'Espagne et des Indes vous n'auriés pas à regretter les places que vous auriés laissées aux anglois pour les engager à faire la paix, je me serviray dans cette vue du pouvoir que vous me donnés [...] Je n'ay pas differé à faire savoir a l'electeur de Bavière le consentement que vous donnés à lui ceder les Pays Bas ${ }^{24}$.

Entre tanto, la negociación bilateral entre Gran Bretaña y Francia avanzaba con paso firme. El 21 de julio Prior y Gaultier estaban en Paris para defender las exigencias británicas y el 18 de agosto Prior y Mesnager se reunieron en Londres para discutirlas. En agosto Luis XIV le remitía a Felipe V los acuerdos con el elector de Baviera y le urgía que le enviara las actas que había que entregarle insistiendo en que aquella era la única vía para conservar las Índias. Se trataba de cederle a su tío y aliado en la guerra la soberanía de los Países Bajos católicos tal como el rey de Francia había previsto en la memoria que libró a Bonnac. Añadía:

vous pouvés juger de ma peine puis que je ne suis pas moins interessé que vous mesme aux changements qui pouroient arriver en Amerique; une promte paix pouroit les prevenir, ainsy je suis persuadé que V. Mté. n'oubliera rien pour faciliter le succés de la negociation commencée lors qu'elle sera instruitte par le Sr. de Bonnac de l'estat de cette affaire ${ }^{25}$.

El 6 de septiembre Felipe V notificaba a Luis XIV que el marqués de Torcy había escrito al conde de Bergeyck para ponerle al día sobre la negociación con Gran Bretaña. Al mismo tiempo le enviaba el documento de cesión de plenos poderes que le había pedido para facilitar los acuerdos preliminares propuestos por los británicos. Aprovechaba la ocasión para aclarar:

23 Zaragoza, 10 de junio de 1711, AHN, Estado, leg. 2460-1, nº 14.

24 Para analizar la correspondencia de Luis XIV a Felipe V, utilizo la obra de GuILlamón Álvarez, F. J., Muñoz Rodríguez, J. D.: La formación de un príncipe de la Ilustración. Selección de la correspondencia privada de Luis XIV a Felipe V durante la Guerra de Sucesión, CAM, 2006. Marly, 22 de junio de 1711, p. 222.

25 Ibidem, Fontainebleau, 17 de agosto de 1711, p. 224. 
si je me suis opposé auparavant à la paix, ce n'a esté que par ce que je ne pouvois l'accepter telle qu' on la proposoit sans me couvrir d'infamie et préjudicier en mesme temps infinement à la France, puisqu'à mon avis sa consérvation dépend, si je l'ose dire, de la mienne sur mon throsne [...] j'espére que vous me l'adoucirez en mésnageant més intérests le plus qu'il vous sera possible et que je n'aurai pas lieu de me repentir d'avoir mis ma confiance en un grand pére que je seais qui a toutes les bontez imaginables pour moy et que j'aime de mon costé avec une tendresse inéxprimable.

No se detuvo ahí y prosiguió en tono más exigente:

J'espére aussi que, si les anglois demandent plus que ce qui n'est porté dans le pouvoir que je vous envoye, vous voudrez bien $\mathrm{m}^{\prime}$ en faire part avant que de vous engager à rien et que je vous le demande comme une chose bien juste, puisqu'il s'agit de ce qui m'appartient. J'ay escrit le plein pouvoir de ma main pour que cela fust plus secret et Grimaldo dont il est contresigné ne seait pas mesme ce que c'est [...] Le M. de Bonnac m'a aussi communiqué un nouveau plan de commerce au quel il m'est impossible de consentir puisque non seulement il osterait entiérement tout les commerce des Indes à 1'Espagne, mais qu'il sen ensuiviroit la perte de Cadis [...] Je vous avoue mesme que cette idée m'a fort surpris et d'autant plus que les anglois n'en ont point parlé du tout. Ainsi je vous prie de n'entrer en aucun engagement sur cela, puis qu'encore un coup je n'y purrois pas consentir ${ }^{26}$.

La respuesta del rey de Francia no se hizo esperar. Expresó a su nieto el deseo de que no se hubiera arrepentido de haberle depositado la confianza y de haber hecho un buen uso de los poderes que le había transferido, puesto que

je vous engage à des conditions que vous n'avés pas prevües; vous verrés qu'elles ne sont pas essentielles et quil estoit necessaire de les accorder pour vous delivrer absolument des instances opiniatrés que les anglois continuoient de faire pour obtenir 4 places dans les Indes. Il y a des occasions quil est important de ne pas laisser eschaper, ainsy ne soyés pas surpris si j'ay interpretté vostre pouvoir sans vous consulter. Il falloit pour avoir la reponse de V. Mté. perdre un tems précieux et je croy travailler utilement pour vous en cedant le moins pour vous conserver le principal que vous consentiés d'abandonner. $\mathrm{J}^{\prime}$ informe le Sr. Bonnac en detail de l'estat de la négociation. Comme il vous en rendra conte il ne me reste qu'a vous assurer que je ne souhaitte pas moins la paix pour vous que pour moy et que je seray content quand je vous veray hereux et solidement estably sur le trone d'Espagne.

En otra carta posterior manifestó su alegría por la partida de Carlos III hacia el imperio, para ser proclamador emperador con el título de Carlos VI, y añadió que Mesnager había regresado con nuevas noticias sobre la negociación, cuyo contenido conocería mediante Bonnac ${ }^{27}$.

\footnotetext{
26 AHN, Estado, 2460-1, nº 15. Corella, 6 septiembre de 1711.

27 Guillamón, op. cit., (nota 24), Versalles, 18 de septiembre y 19 de octubre de 1711, p. 226; en la "Instruction" que el marqués de Torcy envió a sus plenipotenciarios en Utrecht, justificaba que una monarquía tan vasta y compuesta de tantos estados distintos, debía de haber permitido contentar a los dos pretendientes mediante un reparto y de este modo se hubiera evitado la guerra. "Mais cette proposition, odieuse aux
} 
Aún le faltaban por llegar peores noticias a Felipe V. El 30 de noviembre su abuelo le escribió que no sabía cuándo se iniciarían las conferencias de paz ni cuándo los representantes españoles serían recibidos allí. Al respecto, le aconsejaba que desengañara al conde de Bergeyck "de l'idée qu'il a de traitter la paix par la voye des hollandois; laissés moy conduire vos intérets et finissés, je vous prie, l'affaire de l'electeur de Bavière dont je vous assure que le retardement n'est pas honorable a V. Mté. et peut nuire à la negociation". Luis XIV tenía motivos para desconfiar de Bergeyck puesto que se mostró crítico con las directrices francesas e intentó hablar con voz propia. En realidad era partidario de hacer visible la autonomía de España respecto de Francia. En este sentido, además de querer negociar directamente con Holanda, formuló la restitución de los condados del Rosselló, en poder de Francia, se opuso a las patentes necesarias para el duque de Baviera en los Países Bajos y se opuso a que los plenipotenciarios españoles permanecieran en París hasta que se hubieran suscrito los principales artículos de la paz. Bonnac le respondió que el Reino Unido y Holanda -que no reconocían a Felipe $\mathrm{V}$ - no querían concederles pasaportes. Tampoco fueron aceptados los representantes de los electores de Baviera y de Colonia ${ }^{28}$. Sin duda alguna, aquel asunto enrareció las relaciones entre los dos monarcas, hasta el extremo de que Luis XIV amenazó a su nieto de firmar la paz sin contar con España ${ }^{29}$. Al cabo de un mes el rey de Francia abundaba sobre el tema de los pasaportes justificando el retraso:

je ne me suis pas trompé quand jay prevu les difficultés que je trouverois à faire obtenir des passeports à vos plénipotentiaires; je seay quelles sont les mesures que ceux de bon party en Angleterre sont obligés de garder pour assurer le succés de leurs bonnes intentions et contés quils ont fait beaucoup de faire accepter les preliminaires avec les termes que jy ay fait inserer expres pour assurer que vous serés maintenu sur le trone d'Espagne [...] V. Mté. ne doit pas estre surprise si les passeports quelle souhaitte sont encore differés $[\ldots]$ aussy tost que les conférences seront ouvertes je feray les instances necessaires pour les y faire admettre, mais facilités la paix et songés a l'estat ou vous seriés si nos ennemys se reunissoient [...] C'est pour prevenir ce changement que je vous ay fait demander un nouveau pouvoir.

Después de expresarle su alegría por el envío de la patente al elector de Baviera, le regañó por la lentitud con que ejecutaba sus consejos: "je vous assure que je ne feray rien contre vos intérets mais je vous aime trop pour avoir véu sans peine le retardement que vous aportiés à satisfaire à vos engagements" ${ }^{30}$.

\footnotetext{
espagnols, ne leur est devenue supportable que depuis qu'ils ont connu par les évenements la nécessité de faire la paix aux dépens des états que l'Espagne n'a pu conserver [...] ainsi, le partage des États dépendant de la monarchie d'Espagne étant nécessaire, le plan de la paix est principalement fondé sur la manière de convenir de cette séparation [...] le roi, son petit fils, se réservant l'Espagne et les Indes, cédera pour le bien de la paix les autres États dont il a hérité". En otro momento, advertía que el duque de Monteleón "entesté de son nom et de la grandeur de la monarchie d'Espagne, mettrait le point d'honneur à contester tous les démembrements qu'il faudra nécessairement accorde". Legrelle, A.: La diplomatie française et la succession d'Espagne, t. 6. La Paix (1710-1725), París, Imprimerie Zech et fils, 1899, pp. 391-392 y 411, respectivamente.

28 Baudrillart, A.: Philippe V et la cour de France, vol. 1, París, Librairie de Firmin-Didot et Cie, 1890, pp. 436-437; LEGRELLe, op. cit., (nota 27), t. 6, p. 411.

29 Guerrero, op. cit., (nota 6), p. 387.

30 Guillamón, op. cit., (nota 24), Versalles, 30 de noviembre y 28 de diciembre de 1711, pp. 228-230.
} 
A principios de enero de 1712 Luis XIV reclamó un nuevo poder a su nieto, de cuyas cláusulas sería informado por Bonnac y le reiteró: "je vous assure que vous n'aurés pris lieu de vous repentir de la confiance que vous prenés en moy"31. Una semana más tarde volvió a censurarle porque el acta de cesión de los Paises Bajos que le había enviado la había redactado a favor suyo cuando el beneficiario debía ser el elector de Baviera. Como las conferencias de paz estaban a punto de inaugurarse (se iniciaron el 29 de enero) aquel retraso constituía un auténtico contratiempo que debía enmendar rápidamente ${ }^{32}$. Mientras, las noticias que el embajador en París Félix Cornejo enviaba a la corte de Madrid no eran precisamente buenas: "aquí se conserva un gran fondo de mala voluntad contra nosotros y una complacencia extrema en nuestros males". Pero, a los pocos días, con el comienzo de las negociaciones de Utrecht, anunciaba mejores expectativas: "las espereanzas de que se hará la paz se empiezan a fortalecer aquí más y más cada día, confesando ya los más melancólicos que quando no sea universal, la particular entre las tres coronas no puede dejar de concluirse según el favorable curso que han tomado las cosas y la firme resolución en que se mantiene (que es lo principal) la reina británica" ${ }^{33}$.

Unas nuevas instrucciones secretas de Felipe $\mathrm{V}$ al duque de Osuna, de la mano de José de Grimaldo, con fecha de 25 de enero de 1712, resultan muy reveladoras del cambio radical de postura del borbón hispánico en relación con la Instrucción anterior ${ }^{34}$. Después de insistir que defiende sus "intereses por el derecho que me pertenece sobre la monarquía de España y por el interés público del equilibrio que combiene mantener entre las potencias de Europa" alude al acuerdo de las potencias de impedir la reunión de coronas tanto de los Austrias como de los Borbones. A partir de aquí, desgrana sus instrucciones a los plenipotenciarios revisando sustancialmente los puntos de la Instrucción que un mes antes les había expedido. Si bien empieza por reclamar Nápoles, Milán, Cerdeña "y todas las demás partes de la monarquía que mis enemigos an ocupado", añade a renglón seguido que para satisfacer al Archiduque Carlos III pueden ceder Nápoles y Milán "quando no se pudiere de otro modo y comprehendieredes que la oposizión que hazéis puede romper el congreso". En tal caso, deberían procurar que el duque de Saboya conservase la porción del Estado de Milán, al objeto de debilitar el poder de los austriacos. En relación con Sicilia y las dos plazas de Longon y Puerto Hércules en las costas de Toscana, que seguían bajo su control, sostiene que "no tengo lugar de creer que las potenzias marítimas quieran privarme de nada de esto", pero que, en todo caso, "no combendreis en ningún modo en la zesión". En relación con Cerdeña, en posesión de los británicos, piensa que "estos no harán dificultad en restituirmele, mayormente en consideración a lo que ya les tengo conzedido sobre sus requisiziones preliminarias, y assí solicitareis y pedireis esta restituzión por todos los motivos". Respecto a Flandes aclara que ha cedido el territorio a Luis XIV "en consecuencia de un tratado que su Magd. Christianíssima tenía hecho con el duque Elector de Baviera", para quien se deberá pedir la restitución de todos sus estados y dignidades.

\footnotetext{
31 Ibidem, Versalles, 10 de enero del 1712, p. 230

32 Ibidem, Versalles, 18 de enero de 1712, p. 232.

33 Archivo General de Simancas (AGS), Estado, 4309, F. Cornejo a Grimaldo, 18 de enero de 1712 y 25 de enero de 1712, respectivamente.

34 AHN, Estado, leg. 3376 1/2 n o 11 y 12, 25-I-1712.
} 
Acto seguido da cuenta del rumbo irreversible que había tomado la negociación:

el gobierno de Inglaterra a dado prinzipio a la presente negociazión de paz por las proposiciones que hizo al rey mi abuelo en el mes de abril de este año [se refiere a 1711] de que me previno su Magd. por cartas suyas y después su embajador el marqués de Bonnac a su llegada a Corella me comunicó las requisiciones preliminarias que havía hecho aquel gobierno para conseguir la paz y obligar a los holandeses a concurrir a ella. El rey mi abuelo me a hecho comprehender la nezesidad que había de salir de esta guerra por lo exausto que se hallavan sus finanzas, a causa de tantos malos suzesos como havían sobrevenido en el curso de ella. He considerado también el mal estado de mi real hacienda y lo que mis fieles vasallos an padezido hasta aora, que no estava en estado de sostener esta cruel guerra en mis reynos de España y que más valía otorgar algunas ventajas a ingleses en España que exponer otra vez, ni exponer a mis reynos, con la continuación de la guerra a los mismos crueles accidentes.

\section{Por este motivo resolvió enviar a Luis XIV el pleno poder}

que con mucha instanzia y fuerza me havía pedido para combenir con el gobierno de Inglaterra en sus requisiziones preliminarias, en virtud del qual poder sus ministros an venido, por la convención que Dn. N. Mesnager firmó en Londres el día 27 de setiembre pasado de este año [1711], en zeder a Inglaterra por el tratado de paz los puertos de Gibraltar y de Mahón y en que (concluyda la paz) conzedería a ingleses el asiento de negros por un término de trenta años, con las mismas condiziones con que le tienen actualmente los franceses y que se les asegurará un terreno donde podrán no solamente refrescar sus negros, sino guardarlos con toda seguridad hasta que se ayan vendido, y para prevenir que no se use mal de este permiso podré nombrar a un oficial que invigile.

También consintió en que firmada la paz "haré gozar a los ingleses de la ventaja y exempción de los derechos sobre todas las mercancías del producto y fábricas de la Gran Bretaña". Aquella exención no estaba incluida en el poder que envió a Luis XIV, por lo que tuvo que aprobarla, "haviendome Su Magd. participado haverla conzedido, como mucho menos perjudicable que las plazas que pedían ingleses en la América para proteger su comercio". En la medida que perjudicaba a otras potencias, sugería a Osuna que intentara que el Reino Unido desistiera de aquella ventaja “dándoles a entender que será de poca combeniencia para sus súbditos" ofreciéndoles otra ventaja como la prórroga de cinco o diez años más del asiento de negros. Pero matizaba que debía dejar claro que se trataba de un trueque "voluntario y depende de su combeniencia, sin que mi real ánimo sea de alterar en ningún modo lo que sobre esto se a combenido con el rey mi abuelo". Añadía que Luis XIV, a través de Bonnac, le había dado a entender que los británicos estaban dispuestos a restituirle Gibraltar después de la paz, mediante el pago de una cantidad, aunque Mesnager no había profundizado en aquel asunto porque no habían concretado la suma. Ante lo cual, recomendaba ingenuamente: "Hareis diestramente comprehender a los plenipotenciarios de Inglaterra la poca utilidad que pueden sacar de la posesión del puerto de Gibraltar, quando la entrada en él y en todos los demás de España les será libre por la paz, que se puede considerar perpetua por las dos naciones". En caso de que hubiera 
posibilidad de negociar la restitución, deberían pedir el precio e intentar reducirlo "con el motivo de la poca utilidad que podrán sacar en la paz de la posesión de este puerto que les será antes a cargo por la guarnición que les será preciso mantener en él". Finalmente indicaba que para que pudieran discutir con conocimiento de causa, les remitía "la copia de mi poder y de la convenzión que a hecho en Londres dicho Mesnager, según la qual os haveis de reglar puntualmente". Esta era, en definitiva, la pauta que marcaba los lindes de la negociación y que anulaba, en buena medida, las instrucciones que Felipe $\mathrm{V}$ envió a los plenipotenciarios un mes antes.

Al escaso margen de maniobra que dejaban los preliminares acordados entre Francia y Gran Bretaña se sumó el impedimento de que los plenipotenciarios españoles pudieran asistir a las conferencias de paz, a causa de la oposición de los aliados, aunque Francia tampoco hizo nada para resolver aquella situación tan incómoda para Felipe V puesto que a Luis XIV le resultaba mucho más fácil actuar como interlocutor único de los Borbones. En efecto, Torcy escribió a Bolingbroke que Luis XIV consentía que las conferencias empezaran sin los representantes del rey de España, y que su ausencia no perjudicaría ni el desarrollo ni el resultado de las conferencias. No solo eso sino sino que coincidía con el ministro británico que tanto los plenipotenciarios de Felipe V como los del elector de Baviera no debían ser admitidos hasta que los puntos que les afectaban estuvieran ajustados. Torcy pensaba que aquella medida -que le dejaba un amplio margen de maniobra- facilitaría la conclusión de la $\mathrm{paz}^{35}$.

El impasse resultó exasperante para el rey de España puesto que los tres plenipotenciarios que llegaron a París en mayo de 1712 no recibieron los pasaportes hasta marzo de 1713. Osuna, estando en París supo que los británicos irían a la capital francesa a negociar los acuerdos comerciales y predijo lo que iba a suceder: "me parece es la idea el tratar y ajustar aquí todas las cosas pertenecientes a España sin dexarnos pasar al congreso hasta estar todo ajustado, lo que discurro es de grandes inconvenientes y perjuicio, pues no tenemos con quien tratar ni hablar, ni posibilidad de decir ni proponer diferentes cosas combenientes a la España y a los demás". A los pocos días, después de una entrevista con Torcy y de leer la Gaceta de Holanda, dedujo que los franceses "se han alargado todo lo que les ha sido posible tocante a los intereses del rey, de lo que no nos dixo nada el marqués de Torcy el día que estubimos con él" ${ }^{36}$. En efecto, Osuna y el conde de Bergeyck fueron recibidos por el monarca sin que fueran informados de las negociaciones ${ }^{37}$. En agosto de 1712, cuando Bolingbroke, Gaultier y Prior estuvieron negociando en París el acuerdo que propició la suspensión de armas, la situación fue harto incómoda para los plenipotenciarios españoles. En octubre Monteleón reclamó el pasaporte para pasar a Londres, que había solicitado hacía tres semanas, quejándose de "el perxuicio tan grande que se nos sigue, pues se está tratando toda nuestra causa sin la presencia ni persona alguna

35 PARke, G.: Letters and correspondance, public and private of The Right Honourable Henry St. John, Lord Viscont Bolingbroke during the time he was Secretary of State to Queen Anne, London, G.G. and J. Robinson, 1798, vol. 1, Torcy a Bolingbroke, 15-XII-1711, p. 339.

36 AHN, Estado, 3379-1, Osuna a Grimaldo. 10 de febrero de 1712 y 22 de febrero de 1712, respctivamente.

37 AHN, Estado, 3379-1, Osuna a Grimaldo. 29 de febrero de 1712. 
que la defienda" ${ }^{38}$. El plenipotenciario era perfectamente conciente de la importancia de su presencia en la capital británica, donde llegó el 11 de diciembre de aquel año, "donde se fraguan todos los presentes negociados de paces y casi se decide sobre un nuevo sistema de toda la Europa" ${ }^{39}$.

La muerte del Delfín abrió un nuevo frente en la negociación. A principios de marzo, el rey de Francia comunicó su defunción a Felipe V. A partir de aquel momento, el asunto de la separación de las dos coronas pasó a primer plano en la discusión de los acuerdos de paz. El rey de Francia, le avisó: "V. Mté. est presentement regardée de toutte 1'Europe comme prochain heritier de ma couronne et cette opinion generale augmentera les difficultés de la paix". Le confesó que esperaba que pensaría en el bien "d'un royaume qui pouroit vous apartenir un jour" ${ }^{40}$. Pero la renuncia se convirtió en una condición innegociable por parte de los británicos. Bolingbroke la expresó con claridad meridiana a Torcy: "la reine me commande de vous faire savoir que cet article est d'une si grand conséquence, tant pour elle que pour la reste de 1'Europe, tant pour le siècle présent que pour la posterité, qu'elle ne consentira jamais à continuer les negociations de paix, à moins que l'expédient qu'elle a proposé ne soit accepté, ou quelque autre egalement solide" ${ }^{41}$.

Al cabo de un mes Luis XIV advertía a su nieto sobre los obstáculos que impedían la conclusión paz. Pocos días después aclaraba algo más aquella imprecisa afirmación:

les instances de langleterre deviennent plus pressantes sur larticle important dont je vous informai par ma derniere lettre. La necessité de la paix augmente aussy chaque jour et les moyens de soustenir la guerre estant épuisés je me veray enfin obligé de traitter à des conditions egalement desagreables et pour moi et pour V. Mté. si elle ne previent cette extremité en prenant incessament son party sur le conte que le sr. de Bonnac luy rendra de lestat des affaires. Il vous dira ce que je pense dans une conjoncture aussy difficicile qui éxclut toutte sorte de raisonnement ${ }^{42}$.

Según A. Baudrillart, el nieto, disgustado con su abuelo por el tono severo que empleaba con él, se quejó amargamente a Bergeyck rechazando las demandas británicas como si él fuera el vencedor de la guerra y aquellos le debieran un reconocimiento eterno por las concesiones que les otorgaba ${ }^{43}$. Al final Felipe $\mathrm{V}$ respondió a su abuelo, para lo cual Torcy y Bonnac debieron emplearse a fondo. Entonces, manifestó su pesar porque, a su juicio, la búsqueda de la paz a toda costa no hacía más que alimentar el orgullo de sus enemigos, convencidos de que la aceptaría al precio que ellos querrían dársela. Dijo que supo por Bonnac que los británicos habían rechazado las ofertas que les habían propuesto el 18 de marzo y que seguían reclamando su renuncia a la corona de España. Y que era conocedor de las últimas propuestas del

\footnotetext{
3831 de octubre de 1712, AGS, Estado, 4312.

39 Monteleón a Mejorada, 18 de octubre de 1712, AGS, Estado, leg. 6820.

40 Guillamón, op. cit., (nota 24), Versalles, 11 de marzo de 1712, p. 232.

41 PARKe, op. cit.,(nota 35), vol. 1. Bolingbroke a Torcy, 23 de marzo de 1712, p. 439.

42 Guillamón, op. cit., (nota 24), Marly, 9 de abril de 1712, p. 234.

43 Baudrillart, op. cit., (nota 28), vol. 1, p. 485.
} 
secretario de Estado francés, marqués de Torcy, que apuntaban que en caso de que la sucesión al trono de Francia recayera en él, podría elegir entre la corona francesa o la hispánica y que si se daba la primera opción la corona de España podría recaer en el rey de Portugal, en el príncipe que se casara con una de las dos hijas del rey de romanos José, o en el duque de Saboya ${ }^{44}$. Después de expresar sus dudas acerca de que los británicos aceptaran aquellas propuestas, razonaba indignado:

Je ne puis m'imaginer d'un autre costé que la temerité des anglois aille jusqu'à prétendre que j'abandonne dés à présent pour une succession incértaine la posséssion certaine de la couronne d'Espagne et que je me retire en France comme un prince particulier ou à vouloir m'obliger à renoncer à la couronne de France pour moy et pour mes descendants en gardant seulement de toute la Monarchie, l'Espagne et les Indes.

Acto seguido manifestó sin tapujos su disconformidad con aquellos procedimientos: "j' ay esté surpris de voir qu'avant de faire des propositions telles que les derniéres on n'ayt pas songé à en faire qui fussent selon les loix de la succession naturelle" apelando a "l'obligation ou je suis d'avoir esgard au droit naturel et incontéstable que nous avons moy et mes descendants à la succession des deux couronnes". Pero, una vez más, acabó plegándose a los dictados del abuelo no sin dejar de reclamar contrapartidas maximalistas, puesto que consideraba que contribuía a la paz más que nadie en el mundo:

je suis determiné, en cas qu'on ne trouve point d'autre expédient pour conduire la paix à renoncer à la succession de la couronne de France en la manière que vous le jugerez le plus a propos; mais je prétends aussi qu'en considération d'un si grand sacrifice, $l^{\prime}$ Angletere me fasse trouver à la paix de plus grans avantages que ceux qu' elle me veut donner [...] Je demande donc qu'outre l'Espagne et les Indes, la Sicile et les places que je possede actuellement dans la Toscane, on me rende le royaume de Naples, la Sardaigne, l'estat de Milan et les places de Toscane que les ennemis occupen, ou du moins le royaume de Naples avec ces places ou l'estat de Milan. Il faudroit aussi tascher de me faire rendre Gibraltar.

En un post scriptum pedía a su abuelo que puesto que había aprobado la concesión de la soberanía a la princesa de los Ursinos esperaba que él contribuiría a hacer efectiva aquella gracia ${ }^{45}$. Aquel capricho del rey de España alcanzó un protagonismo especial, totalmente desmedido, en la ronda de negociaciones posteriores hasta el punto de bloquear la paz con las Provincias Unidas.

El rey de Francia se impacientaba por momentos, tal como evidencia la carta que envió a Bonnac el 18 de abril de 1712, en la que se lamentaba de que no era justo que acabara arruinando a Francia sólo para garantizar a Felipe V la corona de España o para lograr reunir ambas monarquías, al tiempo que le comunicaba las exigencias británicas: "La paix est absolument rompue si le roi d'Espagne ne renonce à ses droits sur la al couronne d'Espagne. Il ne reste plus qu'à decider si je veux la paix à ce prix

\footnotetext{
44 Memoirs of the marquis of Torcy ..., II, pp. 296-297.

45 AHN, Estado, 2460-1, no 19, Madrid, 22 de abril de 1712.
} 
ou la continuation de la guerre. Comme le second parti ne se pourroit soutenir, je prendrai certainement le premier" ${ }^{46}$. Impaciente, el 28 de abril volvía a presionar a su nieto por partida doble. Por una parte, como aun no había recibido la carta de Felipe V del día 22, le encarecía a dar respuesta a las demandas británicas: "J'espére que vous me mettrés en estat de faire une paix glorieuse en vous conservant la couronne que vous avés sur la teste et qui a dejá cousté tant de sang et tant de dépense". Por otra, le avisaba del deseo del Papa de solventar el conflicto que mantenían y le daba a conocer de forma vehemente su voluntad: "je vous conseille et je vous exhorte, je vous prierois mesme s'il estoit nécessaire, de le terminer promtement pour vostre propre bien" ${ }^{47}$. En aquel asunto Felipe V, llevado de sus impulsos, se metió en un callejón sin salida que conllevó la ruptura de relaciones con el pontífice ${ }^{48}$. Dos semanas más tarde, intentando rebajar el tono, el rey de Francia le aseguraba que se veía obligado a comunicarle verdades muy incómodas aunque no pretendía, en ningun caso, atemorizarle y que no debía tomarlas como una amenaza. Puntualizaba que Bonnac ya le explicaría con toda sinceridad cuál era la situación y cuáles eran los obstáculos que se oponían a las aspiraciones que él había formulado ${ }^{49}$.

En mayo de 1712 reapareció, de la mano de los británicos, el fantasma de la partición de los territorios de la monarquía hispánica. La propuesta obtuvo el beneplácito de Luís XIV pero fue rechazada por Felipe V: el duque de Saboya sería coronado rey de España y Felipe V obtendría Sicília, Piamonte y Saboya, viendo allanado, de esta forma, el camino hacia la corona francesa. ${ }^{50} \mathrm{El}$ emperador había sugerido otra variante a los británicos según el enviado francés en Viena: conceder España y las Índias al duque de Saboya a condición de que otorgara sus estados al emperador y le reconociera el título de rey de España. La operación debía completarse con un matrimonio entre el príncipe de Piamonte y una de las hijas del emperador José ${ }^{51}$. Luis XIV creyó firmemente que Felipe V podía ser coronado rey de Francia y de los estados de Saboya, Piamonte y Montferrate. Escribió al nieto que, a su juicio, sería un magnífico regente durante la minoría de edad del Delfín y que si este moría tempranamente, como era de temer a causa de su débil complexión física, podría convertirse en el heredero. Ello implicaba, naturalmente, la renuncia de España y las Indias. Así lo expresó:

Si la reconnoisance et la tendresse pour vos sujets sont pour vous des motifs pressantes de demeurer avec eux, je puis dire que vous me devés les memes sentiments que vous les devés à vostre maison, a vostre patrie avant que de les dévoir a lespagne. Je vous en demande donc l'effet et je regarderay comme le plus grand bonheur de ma vie

46 Baudrillart, op. cit., (nota 28), vol. 1, pp. 479 y 481.

47 Guillamón, op. cit., (nota 24), Marly, 28 de abril de 1712, p. 236.

48 Sobre el conflicto: Martín Marcos, D.: El Papado y la Guerra de Sucesión española, Madrid, Marcial Pons Historia, 2011; Albareda Salvadó, J.: "Dinasticismo, poltica y religión en la guerra de Sucesión de España”, en Torres, X. (ed.): Les altres guerres de religió. Catalunya, Espanya, Europa (segles XVI-XIX), Girona, Documenta Universitària, 2012, Col·lecció "Papers de 1'IRH”, n”. 2, pp 285-314.

49 Guillamón, op. cit., (nota 24), Versalles, 16 de mayo de 1712, p. 236.

50 BÉLY, op. cit., (nota 10), p. 424.

51 Ministère des Affaires Étragères. Correspondance Politique. Autriche, 91, Pastor, 29-X-1712, fs. 228v229. 
que vous preniés la resolution de vous raprocher de moy et de conserver les droits que vous regretterés un jour inutillement si vous les abandonnés.

Aunque, de forma realista, concluía: “je suis cepéndant engagé a traitter sur le fondement que vous y renoncerés pour conserver seulement 1'Espagne et les Indes si V. Mté. regrette la proposition de leschange avec le duc de Savoie et ce que je puis faire est de vous laisser encore le choix. La necessité de conclure la paix devenant tous les jours pressante" 52 .

Esta vez Felipe V resolvió con determinación. El 29 de mayo respondió a su abuelo:

L'idée qu'elle [V. Mté.] me met devant les yeux de pouvoir me retrouver auprès d'elle seroit bien flatteuse pour moy si je croyois pouvoir embrasser le nouveau party que l'Angleterre me propose, mais trop de raisons s'y oppsosent pour que je puisse l'accepter. Il me semble qu'il est bien plus avantageux à la France qu'une branche de nostre maison regne en Espagne que de mettre cette couronne sur la teste d'un prince de l'amitié du quel elle ne pourroit s'asseurer et cet avantage me paroist bien plus considérable que l'incertitude de réunir un jour à la France la Savoye, le Piedmont et le Montferrat.

Por lo tanto, rechazó el plan británico:

Je donne par la esgalement la paix à la France, je luy asseure pour allié une Monarchie qui sans cela pourroit un jour jointe à ses ennemis luy faire beaucoup de peyne et je suis en mesme temps le party qui me paroist le plus convenable à ma gloire et au bien de mes sujets qui ont si fort contribué par leur attachement et leur zéle à me mantenir la couronne sur la teste ${ }^{53}$.

La réplica de Luis XIV fue tan lacónica como sincera:

Vous decidés par vostre lettre du 29me. du mois dernier la plus importante affaire dont vous puissiés jamaïs avoir à deliberer, je ne puis mempescher d'admirer et de louër l'elevation de vos sentiments, quoy que j'eusse souhaitté vous aimant tendrement que vous eussiés pris un autre party. Je nay pas perdu de temps à faire savoir en Angleterre vostre décision. Elle fera vraysemblament celle de la paix ${ }^{54}$.

La princesa de los Ursinos, a la que recurrió Bonnac como intermediaria en última instancia ${ }^{55}$ comunicó a Torcy que "tous nos efforts ont été également inutiles contre une résolution que S.M. trouve convenir à la religion, à son honneur, à l'intérêt même de la France". Ella misma, había confesado a Bonnac que

le roi d'Espagne ne se trouvoit pas propre à gouverner les François, et qu'il ne se croyoit pas les qualités nécessaires pour soutenir dignement l'éclat que Louis XIV

52 Guillamón, op. cit., (nota 24), Versalles, 18 de mayo de 1712, pp. 238-240.

53 AHN, Estado, 2460-1, n 16, Madrid, 29 de mayo de 1712.

54 Ibidem, Marly, 13 de junio de 1712, p. 240.

55 Guerrero, op. cit., (nota 6), pp. 408-409. 
avoit donné à cette couronne, qu'il s'accoutumoit aux Espagnols, qu'il aimoit les uns à cause de l'attachement qu'il leur connoissoit pour sa personnne, et qu'il ne craignoit pas les autres, connoissant leur foiblesse comme leurs mauvaises intentions ${ }^{56}$.

\section{LA FIRMA DE LOS TRATADOS}

A finales de junio el rey de Francia puso en conocimiento de su nieto que Bonnac le trasladaría las propuestas de los británicos. Ya en agosto, le anunció que la conclusión de la paz dependía de él y de su diligencia. Añadía entonces que

Vous ne devés pas estre etonné de voir que ceux qui s'oposent encore à la paix refusent aussy d'admettre vos plenipotentiaires aux conferences l'un et l'autre part du mesme principe mais la reyne d'Angleterre ne peut mieux faire voir combien elle condanne le procedé de ses alliés qu'en vous envoyant la première un ministre qui prendra le titre d'ambassadeur aussy tost que la paix sera signée ${ }^{57}$.

El 19 de agosto Bolingbroke se reunió de nuevo con Torcy en París y al cabo de dos días acordaron la suspensión de armas y la reanudación de las relaciones diplomáticas entre Londres y Madrid.

Solventados los principales inconvenientes el secretario de Estado británico, el 1 de septiembre, tenía listas las instrucciones para el embajador Lexington, plasmadas en 11 exigencias al rey de España para, a cambio, reconocerlo como tal, entre las que destacan la aceptación de la sucesión protestante, la renuncia a la corona de Francia, el asiento de negros por 30 años, la supresión del impuesto del 15\% sobre productos británicos vendidos en la Indias, la cesión de Menorca y Gibraltar, la cesión de Sicília al duque de Saboya y la amnistía para los austracistas ${ }^{58}$. El comerciante-plenipotenciario Mesnager negoció con Prior y con Arthur Moore, director de la recién creada South Sea Company. Como los británicos habían pedido cuatro puertos en la América española, Mesnager tuvo que compensarlos con un asiento de 30 años en lugar de los 10 que había tenido el asiento francés. Además les prometió que los productos británicos se importarían en todos los puertos de España libres de derechos (aunque Torcy se refiere a "an exemption from de duties of Cadiz and the Indies"), mientras que los aranceles para los otros países eran del 15\% ${ }^{59}$. Esta concesión, efectuada a espaldas de los ministros españoles provocó no pocos problemas hasta que fue substituida, en negociaciones posteriores, por el navío de permiso annual de 500 toneladas a la Indias, libre de derechos y aranceles ${ }^{60}$. A juicio de Stanley J. Stein y Barbara H. Stein "ningún asiento anterior había brindado a un poder europeo una avenida tan ancha

56 BAudrillart, op. cit., (nota 28), vol. 1, p. 498 y pp. 494-495.

57 Guillamón, op. cit., (nota 24), Marly, 24 de junio de 1712; Fontainebleau, 22 agosto de 1712, pp. 242 y 244 , respectivamente.

58 Guerrero, op. cit., (nota 6), pp. 435-444.

59 Memoirs of the marquis of Torcy..., II, p. 154.

60 FERnández, op. cit., (nota 19), pp. 100-103. 
de penetración legítima en el imperio español en América" ${ }^{61}$. El cometido de Lexington en España, a partir del 18 de octubre, aparte de defender aquellas exigencias ante el marqués de Bedmar, era comprobar y levantar acta de la renuncia de Felipe $\mathrm{V}$ al trono de Francia ante las Cortes castellanas. Huelga decir que la posibilidad de negociar directamente con Lexington satisfizo enormemente a Felipe $\mathrm{V}^{62}$.

A los pocos días, el 4 de septiembre, Felipe V comunicaba a Luis XIV:

J'ay deja donné mes ordres pour faire dresser l'acte de renontiation en y adjoutant les deux clauses dont est convenu avec l'Angleterre touchant l'anullation des lettres que vous aviez bien voulu me donner pour conserver mes droits à la couronne de France et la substitution de M. le duc de Savoye et de sa posterité en cas que la mienne vinst à manquer, dans la supposition pour ce que regarde ce dernier point, que l'archiduc fera de son costé à la paix la renonciation qui doit en estre une suite nécessaire. J'ay aussi ordonné la convocation des éstats de mon royaume le 6 $\mathrm{d}^{\prime}$ octobre prochain ${ }^{63}$.

Al cabo de un mes, reiteraba sus argumentos. Después de expresar a su abuelo que esperaba que estuviera satisfecho por las facilidades que había aportado para hacer posible la paz, se quejó de la incomprensión de que había sido objeto su petición de que Carlos VI renunciase a la corona de España. Insistía en que el establecimiento de la sucesión en la casa de Saboya no podía llevarse a cabo a menos que el Archiduque renunciara a sus derechos y que si ello no tenía lugar, el establecimiento no podría ser aprobado como ley en las Cortes que iba a convocar. Acababa manifestando a Luis XIV su satisfacción porque aprobaba las razones por las cuales no era partidario de acordar a los catalanes la conservación de sus leyes ${ }^{64}$.

Felipe V cumplió con la exigencia británica. Formalizada la renuncia a la corona francesa en las Cortes de Castilla, el 5 de noviembre de 1712, ante la presencia de los embajadores marqués de Bonnac y lord Lexington, Luis XIV dejó claro que su nieto había tomado la decisión en contra de su parecer, porque él había confiado en que abandonaría el trono hispánico. Ahora bien, admitió que a consecuencia de ello, «son autorité en deviendra plus absolue en Espagne, ses sujets lui seront plus fidèles" ${ }^{65}$. Por cierto que, en aquellas Cortes, Felipe V impuso mediante procedimientos patrimoniales una ley casi Sálica que alteraba el orden sucesorio establecido en las Partidas y situaba en condiciones de franca inferioridad a las mujeres. El objetivo era evitar que el trono recayera en manos extranjeras ${ }^{66}$. Por su parte, el

\footnotetext{
61 Stein, S., Stein, B. H:. Plata, comercio y guerra. España y América en la formación de la Europa moderna, Barcelona, Crítica, 2000, p. 172.

62 Bergeyck quería ir más lejos y aconsejaba al rey que cuando sus plenipotenciarios fueran aceptados en Utrecht replantearan toda la negociación. BAUDRILLART, op. cit., (nota 28), vol. 1, p. 507.

63 AHN, Estado, 2460-1, nº 17, Buen Retiro, 4 de septiembre de 1712.

64 AHN, Estado, 2460-1, no 18, Buen Retiro, 7 de octubre de 1712; sobre el caso de los catalanes: Albareda, op. cit., (nota 14), pp. 386-418.

65 Morel-Fatio, op. cit., (nota 11), pp. 174-190; Kamen, H.: Felipe V. El rey que reinó dos veces, Madrid, Temas de Hoy, 2000, p. 104; BÉly, op. cit., (nota 10), p. 339.

66 Castellano, J. L.: Las Cortes de Castilla y su Diputación (1621-1789). Entre pactismo y absolutismo, Madrid, Centro de Estudios Constitucionales, 1990, pp. 151-153; Baudrillart, op. cit., (nota 28), vol 1, p. 516.
} 
duque de Orléans y el duque de Berry renunciaron a sus derechos a la corona hispánica $^{67}$. Luis XIV tenía el camino despejado para avanzar decidamente hacia la paz.

A continuación, el 27 de marzo de 1713 Bedmar y Lexington firmaron en Madrid el Tratado preliminar de paz y amistad entre las coronas de España e Inglaterra, un día después de la firma del tratado del asiento de negros. Lo cierto es que el contenido de este último superó las expectativas imaginadas por Bolingbroke hasta el punto de que escribió que el negociador que dio apoyo a Lexington, el comerciante Manuel Meneses Gilligan, merecía una estatua ${ }^{68}$. La South Sea Company, creada en 1711 para financiar la deuda generada por la guerra -la deuda era canjeada a los tenedores por acciones de la compañía- se hizo cargo de la explotación del asiento de negros y del comercio con las Indias españolas ${ }^{69}$. Aquellas cuestiones en las que Bedmar y Lexington no llegaron a un acuerdo, entre otras el caso de los catalanes, la prohibición de que los moros y judíos no pudieran habitar en Gibraltar, sobre la religión en Gibraltar y Menorca, o la creación de un principado para la princesa de los Ursinos, fueron tratadas en Londres por Monteleón (donde llegó el 11 de diciembre de 1712) y Bolingbroke. Torcy, después de lamentarse ante Bolingbroke que "la diligence n'est pas le caractère de la nation [española], et souvent l'ignorance augmente encore sa lenteur naturelle" elogiaba a Monteleón y deseaba que resolviera las dificultades que habían quedado pendientes en la negociación de Madrid ${ }^{70}$. Al final, a pesar de las discrepancias, Monteleón se comprometió con el ministro británico sin atender las últimas instrucciones de Felipe V. De hecho, el plenipotenciario español consideró un gran éxito el resultado alcanzado ${ }^{71}$. Los acuerdos se completaron mediante el tratado de comercio con el Reino Unido del 9 diciembre 1713 que fijaba los aranceles para la importación y exportación ${ }^{72}$.

El 10 de abril, Luis XIV tenía motivos más que suficientes para alegrarse de que Felipe $V$ hubiera firmado el tratado con la reina de Gran Bretaña y le anunciaba que veía cercana la conclusión de la paz, en cuyo proceso consideraba muy importante que los imperiales se hubieran visto obligados a entregarle Cataluña ${ }^{73}$. Al cabo de una semana afirmaba que la paz general de Europa estaba asegurada y que Carlos VI no se hallaba en condiciones de continuar la guerra. Entonces, podía exclamar: "Voyla vostre couronne affermie et vous estes reconnu roy de l'aveu et mesme avec empressement de la part de vos ennemis" 74 . Casi un mes después le informaba de que el emperador rechazaba firmar la paz, al tiempo que le encarecía para que sol-

67 Grell, C.: "Philippe, prince français ou roi d'Espagne: le débat sur les renonciations", en ÁlvarEzOssorio, A., García García, B. J., León Sanz, V.: La pérdida de Europa. La guerra de Sucesión por la Monarquía de España, Madrid, Fundación Carlos de Amberes, 2007, pp. 673-690.

68 Joaquín Guerrero da cuenta, con todo detalle, tanto de los puntos del tratado preliminar como del tratado del asiento de negros: Guerrero, op. cit., (nota 6), pp. 466-479.

69 Sobre el asiento de negros, Fernández, op. cit., (nota 19), pp. 103-147. Y sobre los problemas que conllevó, Ibidem, pp. 138-147.

70 PARKe, op. cit., (nota 35), vol. 2, Torcy a Bolingbroke, 10 de diciembre de 1712, p. 133.

71 Guerrero, op. cit., (nota 6), pp. 493-510.

72 FernÁNDEZ, op. cit., (nota 19), p. 129.

73 Guillamón, op. cit., (nota 24), Versalles, 10 de abril de 1713, p. 248. El 14 de marzo de 1713 fue firmado el Tratado de evacuación de las tropas imperiales.

74 Ibidem, Versalles, 17 de abril de 1713, p. 250. 
ventara las diferencias que aun mantenía con los británicos ${ }^{75}$. Por aquellas fechas Felipe $\mathrm{V}$ podía anunciar a su abuelo que había mandado a sus plenipotenciarios las órdenes pertinentes para la firma de la paz. Ahora bien, no dejaba escapar la ocasión para reivindicar: "Vous jugerez aisement que la paix dont tout le monde désire également la solidité ne peut estre stable si l'Archiduc qui m'a disputé la couronne $\mathrm{d}^{\prime}$ Espagne ne $\mathrm{m}$ 'en reconnoist le legitime roy et il refuseroit peut estre de le faire et de traitter avec moy si il avoit une fois conclu son traitté séparement avec vous". En interés de ambos monarcas, concluía, era preciso soslayar aquel inconveniente ${ }^{76}$.

Francia, Gran Bretaña, Prusia, Portugal, Saboya y las Províncias Unidas sellaron la paz el 11 de abril de 1713. A partir de entonces los plenipotenciarios españoles fueron aceptados y pudieron sumarse al acuerdo el 13 de julio ${ }^{77}$. Osuna llegó el 19 de abril y Monteleón a principios de junio, una vez alcanzados los acuerdos con los británicos en Londres. En Utrecht, las tensiones entre Monteleón y Osuna se hicieron patentes hasta el extremo de que este, en desacuerdo con los preliminares acordados por Bedmar y la negociación posterior de Monteleón, no quería firmar el tratado argumentando que "no habiendo tenido yo intervención sólo sirva para autorizar para la posteridad la destrucción y desmembramiento de la Monarquía"78. La relación entre ambos plenipotenciarios empeoró por momentos hasta límites insostenibles (sin entrar en la materia apuntaremos que Osuna pensaba en términos de defensa de los intererses de España, a diferencia de Monteleón) ${ }^{79}$.

El 30 de julio Luis XIV pudo expresar su alegría a Felipe V por la firma de la paz de España con Gran Bretaña y con el duque de Saboya ${ }^{80}$. Pero no tardó en amonestarle porque había cambiado artículos del tratado con el duque de Saboya que sus propios plenipotenciarios habían firmado: "je souhaitte que le duc de Savoye entre dans vos raisons mais il est en droit de prétendre que la ratification soit conforme au traitté. Il seroit désagréable que cet incident put retarder la paix entre V. Mté. et luy principallement quand vous ne l'avés pas faitte encore avec la Hollande"81. Visiblemente molesto, se quejó a Bonnac en estos términos:

La cour d'Espagne voit à peine quelque apparence de prosperité qu'elle veut tout faire avec hauteur et sans concert, mais aussitôt qu' elle se trouve dans le moindre embarras, les forces lui manquent, et toute sa ressource est de me demander de faire pour elle la guerre à mes dépens. Si elle croit mon assistance nécessaire, il faut au moins que le roi d'Espagne exécute les traités où je me suis engagé en quelque façon por lui ${ }^{82}$.

El rey de Francia retomó el tema al cabo de unos días en una nueva carta a Felipe V: "quand vous y reflechirés je suis persuadé que vous ferés cesser les plaintes

\footnotetext{
75 Ibidem, Marly, 15 de mayo de 1713, p. 250.

76 AHN, Estado, 2460-1, no 20, Madrid, 16 de mayo del 1713.

77 BÉLY, op. cit., (nota 10), p. 428.

78 Guerrero, op. cit., (nota 6), p. 516.

79 FERnÁndeZ, op. cit., (nota 19), pp. 129-130, da cuenta de ellas.

80 Guillamón, op. cit., (nota 24), Marly, 30 de julio de 1713, p. 252.

81 Ibidem, Marly, 21 de agosto de 1713, p. 254.

82 Baudrillart, op. cit., (nota 28), vol. 1, p. 539.
} 
que le duc de Savoye est en droit de faire sur les changements que vous aportés au traitté que vous plenipotentiaires ont signé avec les siens". No fue, este, el único reparo que formuló a su nieto: "vous avés raison de souhaitter de reduire Barcellone par la force, mais quand elle manque la prudence veut qu' on employe d'autres moyens; rien n'est de plus grande consequence pour V. Mté. que de pacifier l'Espagne c'est à vous de juger des voyes qu'il faut prendre pour y réüssir quand vous ne pouvés conter sur le succés de la guerre" ${ }^{83}$. Faltaba más de un año para que Luis XIV, una vez salvado el escollo de la paz de España con las Provincias Unidas, firmada el 27 de junio de 1714, se comprometiera a fondo en la conquista de Barcelona mediante las tropas dirigidas por el duque de Berwick. Antes, Felipe tuvo que desactivar el embrollo del principado en Limburgo que prometió a la princesa de los Ursinos, asunto que reapareció con fuerza en las negociaciones que culminaron en los acuerdos de Rastatt el 7 de marzo de $1714^{84}$. Llevaba razón Bolingbroke: "era ridículo contemplar cómo la paz de dos naciones dependía de la soberanía de madame des Ursins" ${ }^{85}$. Otra vez, Felipe V se vio obligado a claudicar siguiendo los dictados de su abuelo.

En suma, no hay duda de que la negociación de Utrecht fue un asunto de Torcy y Bolingbroke, si bien es evidente que los británicos dictaron las reglas en todo momento $^{86}$. El desenlace de la guerra hizo posible que Luis XIV conservara las fronteras de su monarquía y que consolidara a Felipe V en España. En este sentido Bély sostiene que Utrecht constituyó el desquite francés de las conversaciones de Gertruydenberg (1710), las cuales fueron vividas por los negociadores como una auténtica humillación ${ }^{87}$. Pero es obvio que se trata de una victoria que debe ser considerada en clave dinástica ${ }^{88}$. Además, como señala Reyes Fernández, "los franceses intentaron otorgar lo máximo de la corona española para que el precio francés a pagar fuese el mínimo" 89 .

En lo que concierne a España la resolución del conflicto significó, como bien advirtió Pierre Vilar, la conclusión política de la decadencia, agravada, sin duda, por la pérdida de los territorios italianos, en manos del emperador ${ }^{90}$. No debemos olvidar que el principal objetivo del cardenal Portocarrero y del núcleo que lideró la transición de los Austrias a los Borbones fue la conservación de los territorios de la monarquía en toda su integridad para conjurar la amenaza del tratado de reparto de 1700 acordado por las potencias europeas. Un objetivo a todas luces fallido a la vista del resultado de los tratados de Utrecht y Rastatt, puesto que se asemeja al reparto de los territorios y a las compensaciones económicas previstos por la Gran Alianza de la Haya del 7 de septiembre de 1701. Baudrillart no se anduvo con rodeos a la hora de emitir su juicio al respecto: “jamais monarchie n'a subi démembrements

83 Guillamon op. cit., (nota 24), Marly, 27 de agosto de 1713, p. 256.

84 Albareda, op. cit., (nota 14), pp. 345-355.

85 Guerrero, op. cit., (nota 6), p. 531.

86 BÉLY, op. cit., (nota 8), p. 421.

87 Ibidem, p.463.

88 LynN, op. cit., (nota 18), pp. 359-360.

89 FERnÁNDEZ, op. cit., (nota 19), p. 103.

90 Vilar, P.: Catalunya dins l'Espanya moderna, vol. 2, Barcelona, Edicions 62, 1973 (4),

p. 423 
pareils à ceux que 1'Espagne dut souffrir à Utrecht. La France, sans doute, avait cédé quelque chose elle aussi, mais des possessions lointaines qui n'attegnaient guère sa puissance en Europe, grandie en revanche par l'établissement d'une dynastie française à Madrid." 91 .

\footnotetext{
91 Y apostilla: "Ce que 1'Espagne abandonnait au contraire, c'étaient non seulement d' immenses domaines, les plus riches ou les plus civilisés de ses États, mais tous ses points de contact avec les autres puissances, en dehors de la France; c'est-à-dire tout ce qui jusqu'alors 1'avait mélée à la vie générale de 1'Europe". Baudrillart, op. cit., (nota 28), vol. 1, p. 535. Por su parte Bernardo Ares, concluye que "antes del testamento de Carlos II, Luis XIV fue contra España; después del testamento resolvió sus problemas internacionales a costa de España" en Bernardo Ares, J. M.: Luis XIV rey de España. De los imperios plurinacionales a los estados unitarios (1665-1714), Madrid, Iustel, 2008, p. 186
} 